\title{
COM QUANTOS PAUS SE FAZ UMA CANOA?
}

Mariângela de Andrade Paraizo

$U F M G$

propendemos a tomar por necesidades

las que no son más que repeticiones.

Jorge Luis Borges

\section{RESUMO:}

Neste texto, pretendo trabalhar com o conto "A terceira margem do rio", no contexto do livro Primeiras Estórias, de João Guimarães Rosa, confrontando-o com o filme de Nelson Pereira dos Santos e a música de Milton Nascimento e Caetano Veloso, ambos com o mesmo nome. Os três trabalhos nos mostram o efeito de repetição no processo narrativo. PALAVRAS-CHAVE:

Literatura Brasileira, Cinema Brasileiro, Música Brasileira.

\section{1 - Um esboço}

Há um conto de Guimarães Rosa que se tornou paradigmático na literatura nacional. Um conto que é quase um refrão, que a intervalos mais ou menos espaçados aparece balizando, oferecendo uma referência. $O$ conto é a terceira margem, ou seja, "A terceira margem do rio" é um terceiro vértice, uma metáfora que se incorporou à teoria literária e aos segmentos afins de nossa

I. ROSA, 1972. p. 31-37

REVISTA DE ESTUDOS DE LITERATURA

Belo Horizonte, y. 4, p. 147 - 158 , out. 96 
cultura. E ele continua sendo um ponto que interroga, ele próprio um ponto a menos nessa rede que se formou em torno dele. Este estudo pretende, de novo, responder ao que ele causa.

Todo rio tem duas margens. $O$ rio dessa estória também tinha. Em uma delas ficava a casa que, "no tempo", ainda era mais próxima. A outra margem não se via, de tão largo era esse rio. Na casa, moravam "nosso pai" e "nossa mãe", "minha irmã" e "meu irmão", além, é claro, do narrador dessa história. Um dia, o pai resolve se mudar para o rio, passando a ser uma terceira margem dali. É essa a imagem que ele constrói com sua canoa, que "... saiu se indo - a sombra dela por igual, feito um jacaré, comprida longa"’’.

O pai e o rio são caracterizados pelo silêncio. O rio, "... grande, fundo, calado que sempre" . O pai sempre fora "só quieto" e, depois que resolveu se mudar para a canoa, nunca mais disse nada a ninguém. No dia de sua partida, ainda fez um gesto para o filho-narrador, chamou-o e o abençoou. Depois, nunca mais atendeu aos apelos da família: nem aos esconjuros do padre, nem à intimidação dos soldados, nem às súplicas da filha, quando ela quis the apresentar o primeiro filho. Um dia, e esse é o fím da história, responde, com um gesto, ao aceno de seu filho-narrador, e esse gesto parece vir "da parte de além"'. Essa resposta quebra um encanto: o filho finalmente se afasta da margem desse rio, para sempre. À distância, está contando essa história. Ele, que se define: "Sou o que não foi, o que vai ficar calado", é também "homem de tristes palavras", e o que está "... pedindo, pedindo, pedindo um perdão"”. Ele é quem fala, em contraste com o silêncio do rio e do pai. O narrador, por definição, é quem conta, e o significante, produto de um discurso, faz a margem do simbólico.

Pela escrita, o conto se inscreve nos três registros lacanianos, em que a letra está no real; o significante, no simbólico e o significado no imaginário. ${ }^{8}$ Cabe observar em que medida a terceira margem do rio é a reafirmação dessa tríade nesse conto, a essa margem cabendo o lugar da lei que sustenta o nó dos três registros.

2. Op. cit. p. 32
3. Op. cit. p. 33
4. Op. cit. p. 32
5. Op. cit. p. 32
6. Op. cit. p. 37
7. Op. cit. p. 37
8. LACAN, 1975 . p. 34

Em seu estudo "Análise estrutural de Primeiras Estórias", Maria Luíza Ramos demonstra que,

No levantamento das palavras mais freqüentes ao longo de todas as estórias, vemos que essas palavras se circunscrevem a um mesmo campo semântico, de que o surpreendente poderia perfeitamente ser o denominador comum.

Gostaria de retomar essa questão, pelo viés do conceito de surpreendente, tal como ele se representa nesse conto de Rosa, em que a estranheza fica tributada, pela narrativa, à atitude do pai, embora as reações do filho não sejam menos inesperadas, nem ele mesmo se dando conta do que decide. Para proceder a essa abordagem, quero aproximar os conceitos de surpreendente ou assombroso, do conceito de repetição. Para tanto, recorro a Jorge Luis Borges, para quem "Muchos confunden lo asombroso y lo nuevo, siendo suceso extravagante que entrambos se presenten en una misma obra artística, pues la novedad nunca es áspera y en su principio muestra humilde impureza..."10.

O conto de Rosa articula inusitado e repetido, sob vários aspectos. Por exemplo, do ponto de vista do enredo. A idéia do pai era absolutamente original. Entretanto, ninguém de todo a conhecia, e a constatação de sua intenção - a de permanecer "se indo" entre as duas margens - não se diz, mas se verifica. Não é a partida do pai, mas sua permanência no rio o que dá à família e à gente do local a dimensão do espantoso: "Nosso pai não voltou. Ele não tinha ido a nenhuma parte. (...) A estranheza dessa verdade deu para estarrecer de todo a gente."il

A repetição está também nas imagens construídas pela narrativa: há duas margens no rio, à canoa se soma sua sombra, a "nosso pai" corresponde "nossa mãe", por sua vez reduplicados em "meu irmão" e "minha irmã", e ao pai, instalado na canoa, corresponde o filho, ancorado entre a casa e o rio. Mas a oscilação que se verifica no conto não é da ordem do duplo. É possível pensála como uma oscilação entre oscilações, da mesma maneira que Derrida trabalha o estatuto da Khôra: ..."não é uma oscilação dentre outras, uma oscilação entre

9. RAMOS, 1991. p. 516

10. BORGES, 1994. p. 62

11. ROSA, 1972.p. 33 
cultura. E ele continua sendo um ponto que interroga, ele próprio um ponto a menos nessa rede que se formou em tomo dele. Este estudo pretende, de novo, responder ao que ele causa.

Todo rio tem duas margens. $O$ rio dessa estória também tinha. Em uma delas ficava a casa que, "no tempo", ainda era mais próxima. A outra margem não se via, de tão largo era esse rio. Na casa, moravam "nosso pai" e "nossa mãe", "minha irmã" e "meu irmão", além, é claro, do narrador dessa história. Um dia, o pai resolve se mudar para o rio, passando a ser uma terceira margem dali. É essa a imagem que ele constrói com sua canoa, que "... saiu se indo - a sombra dela por igual, feito um jacaré, comprida longa"3.

O pai e o rio são caracterizados pelo silêncio. O rio, “.... grande, fundo, calado que sempre" . O pai sempre fora "só quieto"s e, depois que resolveu se mudar para a canoa, nunca mais disse nada a ninguém. No dia de sua partida, ainda fez um gesto para o filho-narrador, chamou-o e o abençoou. Depois, nunca mais atendeu aos apelos da família: nem aos esconjuros do padre, nem à intimidação dos soldados, nem às súplicas da filha, quando ela quis the apresentar o primeiro filho. Um dia, e esse é o fim da história, responde, com um gesto, ao aceno de seu filho-narrador, e esse gesto parece vir "da parte de além" . Essa resposta quebra um encanto: o filho finalmente se afasta da margem desse rio, para sempre. À distância, está contando essa história. Ele, que se define: "Sou o que não foi, o que vai ficar calado", é também "homem de tristes palavras", e o que está "... pedindo, pedindo, pedindo um perdão" . Ele é quem fala, em contraste com o silêncio do rio e do pai. O narrador, por definição, é quem conta, e o significante, produto de um discurso, faz a margem do simbólico.

Pela escrita, o conto se inscreve nos três registros lacanianos, em que a letra está no real; o significante, no simbólico e o significado no imaginário. ${ }^{8}$ Cabe observar em que medida a terceira margem do rio é a reafirmação dessa tríade nesse conto, a essa margem cabendo o lugar da lei que sustenta o nó dos três registros.

$$
\begin{aligned}
& \text { 2.0p. cit. p. } 32 \\
& \text { 3. 0p. cit. p. } 33 \\
& \text { 4. 0p. cit. p. } 32 \\
& \text { 5. 0p. cit. p. } 32 \\
& \text { 6. } 0 \text { p. cit. p. } 37 \\
& \text { 7. } 0 \text { p. cit. p. } 37 \\
& \text { 8. LACAN, } 1975 \text {. p. } 34
\end{aligned}
$$

Em seu estudo "Análise estrutural de Primeiras Estórias", Maria Luíza Ramos demonstra que,

No levantamento das palavras mais freqüentes ao longo de todas as estórias, vemos que essas palavras se circunscrevem a um mesmo campo semântico, de que o surpreendente poderia perfeitamente ser o denominador comum.

Gostaria de retomar essa questão, pelo viés do conceito de surpreendente, tal como ele se representa nesse conto de Rosa, em que a estranheza fica tributada, pela narrativa, à atitude do pai, embora as reações do filho não sejam menos inesperadas, nem ele mesmo se dando conta do que decide. Para proceder a essa abordagem, quero aproximar os conceitos de surpreendente ou assombroso, do conceito de repetição. Para tanto, recorro a Jorge Luis Borges, para quem "Muchos confunden lo asombroso y lo nuevo, siendo suceso extravagante que entrambos se presenten en una misma obra artística, pues la novedad nunca es áspera y en su principio muestra humilde impureza..."10.

O conto de Rosa articula inusitado e repetido, sob vários aspectos. Por exemplo, do ponto de vista do enredo. A idéia do pai era absolutamente original. Entretanto, ninguém de todo a conhecia, e a constatação de sua intenção - a de permanecer "se indo" entre as duas margens - não se diz, mas se verifica. Não é a partida do pai, mas sua permanência no rio o que dá à família e à gente do local a dimensão do espantoso: "Nosso pai não voltou. Ele não tinha ido a nenhuma parte. (...) A estranheza dessa verdade deu para estarrecer de todo a gente."ll

A repetição está também nas imagens construídas pela narrativa: há duas margens no rio, à canoa se soma sua sombra, a "nosso pai" corresponde "nossa mãe", por sua vez reduplicados em "meu irmão" e "minha irmã", e ao pai, instalado na canoa, corresponde o filho, ancorado entre a casa e o rio. Mas a oscilação que se verifica no conto não é da ordem do duplo. É possível pensála como uma oscilação entre oscilações, da mesma maneira que Derrida trabalha o estatuto da Khôra: ..."não é uma oscilação dentre outras, uma oscilação entre

9. RAMOS, 1991. P. 516

10. BORGES, 1994. p. 62

11. ROSA, 1972. p. 33 
dois pólos. Ela oscila entre dois gêneros de oscilação: a dupla exclusão (nem nem) e a participação (ao mesmo tempo...e, isto e aquilo)."12

Esses dois gêneros de oscilação são facilmente localizáveis no texto de Rosa: "ele não figurava mais estúrdio nem mais triste" ou "Sem alegria nem cuidado"|3, a que se contrapõe: "existir, perto e longe de sua família dele"|4, ou "Os tempos mudavam, no devagar depressa dos tempos"'s, ou ainda "Ao por fim, ele apareceu, ai e lá, o vulto. (...) Estava ali (...) da parte de além"'l6. A atopia é ainda uma localização, uma ubiqüidade.

A terceira margem do rio desconstrói o espaço do conto, é uma inscrição do atópico no território familiar. Desconcerta. Assim, para melhor abordá-la, vale a pena fazer uma ligeira incursão em outros contos de Rosa, que também fazem parte de Primeiras Estórias, e tentar localizar outras referências.

Desde o título, o conto "As margens da alegria"l" parece responder a essa procura de semelhanças. Novamente a idéia de margens, inclusive no tempo: esse conto começa e termina nas horas limítrofes, manhãzinha e entardecer, e situa-se à margem da construção de Brasília. Nos dois contos, vê-se a presença dos tios. Como em "A terceira margem do rio", o menino fica sob os cuidados do irmão da mãe A maior surpresa do Menino acontece com o surgimento de um peru, “... o peru para sempre. (...) Sua ríspida grandeza tonitruante."18 . Esse peru é sacrificado, e no terreirinho, onde ele ficava, o Menino vê um outro. "Não era o mesmo. Menor, menos muito. (...) Sua chegada e presença, em todo o caso, um pouco consolavam.",

A associação entre pai e filho, evocada pelos dois perus - relação metafórico/metonímica bastante obvia, respaldada pelo imaginário popular parece repetir a imagem das duas canoas: a do pai, madeira de lei, cuja sombra era "comprida longa", e a do filho, "uma canoinha de nada", que ele espera merecer "no artigo da morte" 20 . Mas o que reforça a associação é a culpa. Em

\footnotetext{
12. DERRIDA, 1995. p. 13

13. ROSA, 1972. p. 32

14. Op. cit. p. 33

15. Op. cit. p. 35

16. Op. cit. p. $36-37$

17. Op. cit. p. $2-7$

18. Op. cit. p. 4

19. Op. cit. p. 7

20. Op. cit. p. 37
}

"As margens da alegria", o terreirinho "... era uma saudade abandonada, um incerto remorso". Ao vislumbrar a cabeça degolada do peru, o Menino “... se dóa e se entusiasmava". E o peru menor, esse era atraído por essa cabeça "... por um ódio"2l. Essa ambivalência se repete em "A terceira margem do rio". O filho, depois de seu "falimento" " perdão". Mas, mesmo antes, ele interroga: "De que é que eu tinha tanta, tanta culpa?"'s

Trabalhando com "As margens da alegria", Eneida Maria de Souza destaca o final desse conto:

A aparição inusitada do peru e seu efeito de deslumbramento provocado no Menino apaga-se com a sua morte e imediata transformação em alimento, decepção logo recalcada pela visão de outro peru. A luzinha verde do vagalume, vinda da mata, instaura o jogo do visível e do invisível, em que a sensação de alegria se traduz no exercício intermitente de presença e ausência. ${ }^{24}$

Esse mesmo jogo parece ser o que está em questão no conto "Partida do audaz navegante" 15 , quando Brejeirinha batiza a "Ilhazinha dos Jacarés": "Você já viu o jacaré lá?" - caçoava Pele. - "Não. Mas você também nunca viu o jacaré-não-estar-lá. Você vê é a ilha, só. Então, o jacaré pode estar ou não estar..." ${ }^{26}$ A imagem do visível e do invisível parece chegar às últimas consequiências na proposta de fazer ver o não. No conto "A terceira margem do rio", essa é uma função do pai, “... o meu pai, sempre fazendo ausência"" faz a ausência não é mais "nosso" pai, esse que é dividido com os irmãos, mas o "meu" pai. Mais próximo, mais distância.

Outro conto que aborda uma terceira margem é "Pirlimpsiquice"20. Lá, havia uma peça a ser representada: "Os filhos do Doutor Famoso".
21. Op. cit. p. 7
22. Op. cit. p. 37
23. Op. it. p. 36
24. SOULA, 1993, p. 153
25. ROSA, 1972. p. 114-123
26. Op. cit. p. 119
27. Op. cit. p. 36
28. Op. cit. p. $38-48$ 
Novamente o pai, os filhos. Um garoto de nome Ataualpa representaria o Doutor Famoso, mas seu pai estava à morte, seu tio foi chamá-lo. Por essa razão inesperada, quem vai representar o papel do pai desses filhos é o narrador da história. Só que ele não sabe o preâmbulo de sua fala e, na hora em que a representação começa - "Eu estava ali, parado, em pé, de fraque, a beira-mundo do público, defronte." - dão-lhe ordem para começar, mas ele não pode: “... explicavam-me o que eu já sabia que não sabia, não podia." ${ }^{\prime 2}$. $O$ espetáculo, então, corre à revelia do texto, de qualquer texto previsto. A peça encenada é inventada na hora. Julgando que era necessário intervir para dar fim a essa representação, o narrador se precipita: "Cheguei para a frente, falando sempre, para a beira da beirada. Ainda olhei, antes. Tremeluzi. Dei a cambalhota. De propósito, me despenquei. E caí." ${ }^{30}$ A personagem interfere da "beira da beirada", fazendo a margem do texto com seu próprio corpo. Mais exatamente, com seu desfalecimento.

Há outras referências nos contos de Guimarães Rosa que repetem elementos da terceira margem. Por exemplo, este cenário, de "Nenhum, nenhuma" ${ }^{\text {: }}$ : "A mansão, estranha, fugindo, atrás de serras e serras, sempre, e à beira da mata de algum rio, que proibe o imaginar. ${ }^{.32} \mathrm{O}$ estranho como elemento estruturante, a casa entre a mata e o rio, o interdito, a fuga, o sempre, o imaginado e a proibição. A casa - nesse caso, a mansão - "atrás de serras e serras", lembra o Mutum, "entre morro e morro" ${ }^{33}$. E esse lugar entre, causado pela repetição e sua impossibilidade, permeia a obra de Rosa. Há, em "Famigerado"34, uma construção-síntese desse topos: "O medo O." ${ }^{.35}$

A terceira margem parece intervir justamente nesse ponto entre, produzindo a atopia, provocando a crise e o subseqüente discernimento. Numa primeira instância, tudo parece ilimitado, desbordado, o "oco sem beiras"36 que experimenta Sorôco, no conto que tem seu nome, junto com sua mãe e sua

29. Op. cit. p. 45

30. Op. cil. p. 47

31. 0p. cit. p. 49-57

32. Op. cit.p. 50

33. ROSA, 1976. p. 5

34. ROSA, 1972. p. 8-13

35. Op. cit. p. 9

36. Op. cit. p. 18

37. Op. cit. "Sorốco, suo mäe, sua filho". p. 14-18 filha ${ }^{37}$. Há um segundo momento de vacilação, em que o protagonista nem é inocente nem sabe de que é culpado, e, finalmente, a terceira variante, a oscilação entre o isto e aquilo e o nem/nem. À oscilação entre o ou/ou, "ou a bolsa ou a vida", Lacan chamou o véu da alienação. Quando o significante se produz, o sujeito cai e é barrado, tentando suturar o lugar do objeto. Tudo recomeça? De novo.

Para contornar a crise, a estratégia proposta em "A terceira margem do rio" é a representação. De um lado, o não-saber do filho; de outro, o nãotodo da verdade. Assim, quando louvam o filho por algum bom procedimento, ele diz que foi seu pai quem um dia lhe ensinou, “... o que não era o certo, exato; mas, que era mentira por verdade. ${ }^{\prime 38}$ Ele sabe da estrutura de ficção que a verdade tem, ainda que através de um saber não sabido. Quando a família simulava que se esquecia do pai - "a gente fazia que esquecia" $a^{39}$ - era só para renovar a lembrança. E a simulação será sua isca para atraí-lo. Quando o pai fora para o rio, ele, por um propósito sem propósito, havia perguntado se poderia ir junto. Não podia. "Fiz que vim, mas ainda virei, na grota do mato, para saber." saber, não é apenas o voltar-se que conta, mas o fingimento, a própria representação, o "fiz que vim, mas ... ". Do mesmo procedimento ele vai se valer no final, quando "Só fiz, que fui lá.". Ele finge saber o porquê da permanência do pai no rio, propondo-lhe substituí-lo. Dito de outra maneira, ele o imita. O gesto do pai é uma afirmativa, mas responde ao que ele não sabe. $O$ gesto do filho retorna como a promessa de um saber e atinge seu corpo onde ele não responde. A metáfora paterna é um limite à representação. Por parecer vir "da parte de além", o gesto do pai caracteriza-se como Unheimlich, o que veio à tona, mas que deveria permanecer submerso."

Do ponto de vista do narrador, é claro que toda narração é uma representação, uma forma que se dá ao fato. O narrador de "Nenhum, nenhuma" explicita um propósito: "Se eu conseguir recordar, ganharei calma, se conseguisse religar-me: adivinhar o verdadeiro e real, já havido." ${ }^{142}$ Narrar é a estratégia para representar o verdadeiro e provocar a emergência do real. Quando o narrador de "A terceira margem do rio" diz: "Sou o que não foi, o que vai ficar calado"/3 - definição que, aliás, parece corresponder ao texto bíblico, "Eu sou aquele que é" - o narrador se contradiz. Calar-se é fazer silêncio, um silêncio significante.

\author{
REVISTA DE ESTUDOS DE LIIERAIURA \\ Belo Horizonte, v. 4, p. 147 - 158, out. 96 \\ 38. Op. cit. p. 35 \\ 39. Op. cit. p. 35 \\ 40.0 . cit .33 \\ 41. FREUD, 1985. . . 246
}


Calar a palavra "doido" é enquadrar, em negativo, o pai e seu procedimento. Silenciar é com o rio e com o pai.

A escrita do conto é o arcabouço de sua representação. É disso que se trata na literatura. A letra assegura que haja uma história à qual podemos voltar, o que empresta à repetição o caráter de uma instância do real, embora, por estrutura, a repetição seja eminentemente simbólica, um efeito da narração e não propriamente da escritura. É o narrador, e não o autor, que permeia a leitura de um texto. A relação com a letra ocorre justo no ponto em que repetição evoca lei, como afirma Deleuze: "A lei reúne a mudança das águas à permanência do rio." "'4 Num terceiro registro, no imaginário, a repetição pode ser necessária ou contingente. Sabendo-se que a repetição nunca faz o mesmo, faz de novo, o desejo de repetir, ou a compulsão à repetição, comportam certa medida de ilusão. Lê-se em Heráclito: "No mesmo rio entramos e não entramos; somos e não somos."'s , e em Rosa: "Assaz o senhor sabe: a gente quer passar um rio a nado, e passa; mas vai dar na outra banda é num ponto muito mais em baixo, bem diverso do em que primeiro se pensou."'46

\section{2 - Outros traços}

Este conto, "A terceira margem do rio", foi adaptado para o cinema por Nelson Pereira dos Santos" ${ }^{77}$, sofrendo várias modificações. O filme também se chama A terceira margem do rio e quatro outras das Primeiras Estórias ${ }^{48}$ foram enxertadas em seu enredo: "A menina de lá", "Os irmãos Dagobé", "Fatalidade" e "Seqüência". Na nova linguagem que recebeu, o fantástico do sertão das Gerais ganha ares de realidade virtual e dimensões espetaculares.

As cenas em que se enfoca o conto "Seqüência" são marcadamente subjetivas. Por exemplo, quando a vaquinha-pitanga está fugindo e segue a nado pelo rio, perseguida pelo cavalo e pelo cavaleiro, o filtro utilizado empresta

\author{
42. ROSA, 1972. p. 51 \\ 43. Op. rit. p. 37 \\ 44. DELEUZE, 1988. p. 23 \\ 45. HERÁCLITO, 1980. p. 81 \\ 46. ROSA, 1974. p. 30 \\ 47. SANTOS, 1994 \\ 48. ROSA, 1972. p. 19-24, p. 25-30, p. 58-63, p.64-69, respectivomente.
}

uma atmosfera mística ao filme, um clima de prenúncio e travessia, próprio da obra de Rosa, confirmado no desenrolar dos fatos. O rapaz entra na casa desconhecida, e lá está a moça, sob a luz da sala. A câmara acompanha o foco dos olhos enamorados, contando com a cumplicidade dos presentes que apenas acompanham a cena com os olhos. Os figurantes formam um quadro vivo, mais próximo de se incorporarem ao cenário que de se tornarem personagens. Toda a seqüência se reveste de um clima de magia, bem próximo ao que se encontra no conto, em que a vaquinha, por amor, por um propósito só seu, é responsável pelo encontro dos dois jovens, "o mel do maravilhoso (...) o anel dos maravilhados" ${ }^{\prime 4}$.

Mesmo o que não há, no texto de Rosa, acontece, no filme de Santos. Há uma mudança de perspectiva, especialmente nos contos "A menina de lá" e "Os irmãos Dagobé". No caso do primeiro, o que eram milagres caseiros, de domésticas proporções, crescem, tornam-se públicos e dão lugar a uma peregrinação. No segundo conto, os valentes do arraial ganham foros de poderosos inimigos públicos, no Distrito Federal, com a conivência da polícia e um envolvimento com o narcotráfico. $O$ caráter de espetáculo é garantido pela presença da televisão, que faz a cobertura $\mathrm{e}$ a promoção dos acontecimentos que os reúnem. Há um momento em que a câmara, no filme, faz uma tomada em close da tela da tv, que apresenta a vinheta do jornal da Manchete. Essa tomada causa o impacto da superposição de linguagens. A tela do televisor serve, ainda, para um efeito de realidade virtual quando caem no colo da menina e sua avó os bombons de uma propaganda.

O conto "A terceira margem do rio" está no começo, no final e no título do filme, permeado pelas outras estórias, enredando-as. Há uma declaração de Nelson Pereira dos Santos, na contra-capa da fita de vídeo. Este trecho explicita a proposta do filme:

Por que o homem abandona a família e vai viver no meio do rio? São indagações que não procurei responder. Talvez a terceira margem do rio seja o que todo mundo procura e não sabe o que é. Quis mostrar que talvez exista uma terceira margem para o Brasil, entre o velho e o novo. ${ }^{50}$

No filme, o filho tem um nome e constrói sua própria vida: casa-se, tem uma filha e mata um homem. Deixa seu pai e vai viver por um tempo às 
margens da construção de Brasília, sempre na companhia da mãe. Suas atitudes e seus deslocamentos são uma espécie de fio condutor que permite a inserção dos outros contos. A personagem não tem, como no texto de Rosa, a função de narrador, mas a câmara segue seus passos que vão relacionando as estórias.

Nos episódios relativos à terceira margem, o rio é uma metonímia do pai, já que em alguma parte ele assiste. Quando querem falar ao pai, é ao rio que se dirigem. As cenas em que o filho mostra ao rio os alimentos que trouxe a seu pai, aquela em que apresenta sua mulher e, mais tarde, sua filha, por exemplo, explicitam um raciocínio muito próximo ao pensamento mágico. O pai é o grande ausente, que ninguém vê e que parece ver e ouvir a todos. $E$ isso basta às personagens envolvidas nesse enredo, já que ninguém se indaga sobre os motivos do pai ou o sentido de sua permanência na canoa. Entretanto, na última cena, o pavor do filho ante a resposta afirmativa do pai é bastante fiel ao conto, o que permite presumir que é melhor não encontrar "o que todo mundo procura e não sabe o que é".

As músicas do filme são de Milton Nascimento, e a música tema, que leva o mesmo nome do conto e do filme, foi feita em parceria com Caetano Veloso ${ }^{51}$. A música não conta o enredo da estória, mas reproduz, sob vários aspectos, a questão colocada no conto de Rosa. Trata-se de um trabalho intertextual bastante feliz, em que o conto é desconstruído para dele emergir uma canção.

Com uma forma muito mais nominal do que verbal, a letra da música tem um caráter marcadamente metonímico e, além de ser em versos, é feita de frases entrecortadas, em que as idéias insinuadas vão se formando mais pela repetição que pela exposição.

A repetição acontece de várias maneiras. Ocorre nos versos, nas estrofes, e na retomada das frases e sequiências musicais, que se organizam como tema e variações. Nos versos, a repetição se dá através da exploração de assonâncias e aliterações, como em "Eu sou madeira, beira / Boa, dá vau...", ou através do efeito de eco proporcionado, por exemplo, pelas palavras "asa", "casa" e "brasa", dispostas em versos consecutivos. Há, inclusive, a repetição de sons através de um anagrama: "terceira" e "certeira". Além, é claro, da insistência em palavras-chave como "rio", "pai", "Rosa" e "palavra".

O rio é o limite entre pai e filho. Tanto ele como o pai são silenciosos, tanto ele como o filho são testemunhas. Por isso ele reúne o estatuto do silêncio

51. MASCMENTO E VELOSO, 1992 a voz das águas, o que permite a construção paradoxal: "Casa da palavra / Onde o silêncio mora". A estrutura de paradoxo, mais exatamente de aporia, é inerente ao texto de Rosa. É conseqüência da oscilação entre oscilações, que transforma alternativas em circunstâncias de impedimento.

Uma característica tanto da letra quanto da música é o corte, o entremear do silêncio à canção. No arranjo gravado por Caetano Veloso, essas breves interrupções são mais evidentes, mais marcadas pela voz e instrumentos. Nos versos, além da cesura natural que os estrutura, há dois momentos privilegiados para se observar o corte, como junção e como ruptura. Há um neologismo, a palavra "tristriz", feita pela justaposição de "tris", onomatopéia para ruído de coisa que se parte, especialment vidros, e "triz", usada na expressão "por um triz", com o sentido de um "quase nada" "52. Tristriz é uma palavra bastante compatível com o pânico do filho, no final da estória, quando algo, um quase nada, rompeuse, para sempre. E há uma palavra partida, neste outro verso: "Meio a meio o rio ri". O riso, um corte na palavra rio, faz outra margem nas águas da canção.

No conto, a ruptura é provocada pelo gesto de assentimento do pai. É depois dele que o filho pode partir e contar sua história. O que na canção se evidencia é que o corte, mais que um recurso, é o que dá o sentido do texto. A palavra tem sua flor, que é "Rosa da palavra". "À flor das águas" - "água de Rosa", a palavra navega, tem proa. Rosa é nome do autor, e escrita evoca a letra, um corte significante. A canoa e a letra, cortando a "água da palavra", riscam a terceira margem.

Para terminar, o último verso da canção: "Rio, pau enorme, nosso pai". O verso parece condensar pelo menos duas leituras. Pode-se pensar numa seqüência de imagens: uma panorâmica do rio, depois a câmara focaliza a canoa e o pai. É quase assim que começa o filme. Milton está cantando a música tema, durante a exposição dos créditos, e o espectador vê as imagens do rio, vai seguindo seu curso. A canção termina, e lá está o pai embarcando, abençoando o filho, na despedida da família. Mas também se pode pensar que, neste último verso, as três expressões se equivalem, uma sendo o aposto da outra. São três expressões nominais, nenhum verbo dá o tempo da estrutura, que, parece, se eterniza. São traços metonímicos que esboçam uma construção fantasmática. Com uma ou outra leitura, não está longe o sentido desta terceira margem no rio, um momento de revelação sobre com quantos paus se faz uma canoa. Ainda citando Guimarães Rosa, “.... onde é bobice a qualquer resposta, é aí que a pergunta se pergunta" ${ }^{\prime 3}$. De novo, uma travessia.

\section{FERREIRA, 1951.}

53. ROSA, 1974. p. 86
REVISTA DE ESTUDOS DE IITERATURA Belo Horizonte, v. 4, p. 147 - 158, out. 96 
ABSTRACT:

In this paper, $I$ intend to exploit the tale "A terceira margem do rio", in the context of João Guimarães Rosa's book, Primeiras estorias, and in opposition to a Nelson Pereira dos Santos's film and a Milton Nascimento and Caetano Veloso's song, both of them having the same name of the tale. All these pieces show us the effect of repetition KEY WORDS:

in the meaning of the narrative.

Brazilian Literature, Brazilian Cinema, Brazilian Music.

\section{MUDANÇA DE MAPA, MUDANÇA DE TERRITÓRIO NA COMUNIDADE IMAGINADA DE JOÃO ROSA}

Marli de Oliveira Fantini Scarpelli

UFMG

\section{RESUMO:}

Este trabalho pretende demonstrar que, na novela "Uma estória de amor", de João Guimarães Rosa, a geografia simbólica se desloca, provocando o esboroamento das noções holísticas de territoriedade. Ao encenar, na novela, uma travessia poética, João Rosa insere a paisagem cerrada do sertão no seu modelo de universo: um sertão multicultural, seu império suevo-latino. Na constelaridade vertiginosa da narrativa/festa/viagem, as estórias proliferam e se intercambiam umas às outras, nada deixando fixar. $A$ comunidade imaginada do autor - a partir da negociação das diferenças - interrompe o continuum da cultura, inscreve-se numa cartografia imaginária, para inaugurar um novo território. PALAVRASCHAVE:

Viagem, Festa, Território, Fronteira, Diferença.

Ao demandar uma literatura tão ilógica quanto a sua, "que transforme o cosmo num sertão"', João Guimarães Rosa traça sua cartografia imaginária, a partir de cuja demarcação se podem reconhecer os limites de seu território

1. ROSA, 1994, p. 57.

REVISIA DE ESTUDOS DE LUERATURA

Belo Horizonte, v. 4, p. 159-168, out. 96 